\title{
Changes in catastrophizing and kinesiophobia are predictive of changes in disability and pain after treatment in patients with anterior knee pain
}

\author{
Julio Doménech • Vicente Sanchis-Alfonso • \\ Begoña Espejo
}

Received: 12 October 2013 / Accepted: 19 March 2014

(C) Springer-Verlag Berlin Heidelberg 2014

\begin{abstract}
Purpose The purpose of the study was to investigate if changes in psychological variables are related to the outcome in pain and disability in patients with chronic anterior knee pain.

Methods A longitudinal observational study on 47 patients with chronic anterior knee pain was performed in a secondary healthcare setting. Pain was measured with the visual analogue scale and disability with the Lysholm scale. The psychological variables, such as anxiety, depression, pain coping strategies, catastrophizing and fear to movement beliefs, were studied by using self-administered questionnaires.

Results Among the pain coping strategies, only the catastrophizing subscale showed a significant reduction. Similarly, anxiety, depression and kinesiophobia were significantly reduced after treatment. Those patients who decreased the catastrophizing, kinesiophobia, anxiety and depression showed a greater improvement in pain and disability after a purely biomedical treatment. A multiple
\end{abstract}

\footnotetext{
J. Doménech · V. Sanchis-Alfonso ( $ه)$

Department of Orthopaedic Surgery, Hospital Arnau de Vilanova, C/San Clemente \#12, 46015 Valencia, Spain e-mail: vicente.sanchis.alfonso@gmail.com

J. Doménech

Facultad de Ciencias de la Salud, Universidad CEU-Cardenal Herrera, Moncada, Valencia, Spain

V. Sanchis-Alfonso

Hospital 9 de Octubre, Valle de la Ballestera 59,

46015 Valencia, Spain

B. Espejo

Department of Methodology of the Behavioural Sciences, Facultad de Psicología, University of Valencia, Valencia, Spain
}

regression analysis revealed that changes in catastrophizing predicted the amount of improvement in pain severity and that changes in both catastrophizing and anxiety predicted changes in disability after treatment.

Conclusion What has been found suggests that clinical improvement in pain and disability is associated with a reduction in catastrophizing and kinesiophobia. Therefore, co-interventions to reduce catastrophizing thinking and kinesiophobia may enhance the results.

Level of evidence Prospective Cohort Study, Level I for prognosis.

Keywords Anterior knee pain - Patellofemoral pain . Kinesiophobia · Catastrophizing $\cdot$ Anxiety $\cdot$ Depression

\section{Introduction}

Anterior knee pain is one of the most frequent reasons for consultation within knee conditions in adolescents and young adults [25]. However, despite the high prevalence of this disorder, its pathogenesis and therefore its treatment are not clearly understood [30]. In fact, the results of the treatment, both conservative and surgical, are unpredictable, and many patients may continue to experience significant pain and disability following a correct treatment.

To date, it is well accepted that anatomical alterations (severe patellofemoral malalignment, severe patellar chondropathy) cannot fully account for pain and disability in anterior knee pain patients [30]. Biopsychosocial models of pain suggest that a complete understanding of chronic pain requires consideration of anatomical, psychological and social factors [18]. A cross-sectional study in anterior knee pain patients showed that an excessively negative orientation towards pain, that is, the belief that pain will get 
worse and that one is helpless to deal with it (catastrophization) and the belief that movement will create additional injury or re-injury and pain (kinesiophobia), is associated with pain intensity and disability in these patients [8] as occurs in other chronic pain patients [38]. Riddle et al. [27] have demonstrated that high levels of pain catastrophizing have been shown to predict post-surgical pain and poor function in patients with a knee arthroplasty. In a longitudinal study by Piva et al. [24] fear-avoidance beliefs turned out to be the strongest predictor of functional outcome in a series of anterior knee pain patients, even greater than biomechanical and structural variables. Chmielewski et al. [5] have shown that the decrease in fear of movement or reinjury may have potential to improve short-term outcomes for knee pain and function after anterior cruciate ligament reconstruction. On the basis of these observations, we believe that psychological factors (catastrophization, kinesiophobia, anxiety and depressive symptoms) may be overlapping or unique risk factors for poor results in the treatment of anterior knee pain patients. We hypothesize that after treatment, a change in pain and disability will be correlated with a change in pain coping strategies, cognitions and emotions about pain that can explain the amount of change in the functional outcome.

To our knowledge, there are no previous studies in anterior knee pain patients that analyse changes in pretreatment measures of pain, disability, kinesiophobia, catastrophization, anxiety and depressive symptoms after traditional biomedical treatment. The objective of the present study is to investigate if changes in psychological variables are related to the outcome in pain and disability in patients with chronic anterior knee pain.

\section{Materials and methods}

During a 1-year period, all consecutive patients with anterior knee pain referred to our orthopaedic surgery consultation were invited to participate in the study. Inclusion criteria were age from 18 to 50 years, pain perceived in the anterior aspect of the knee following exclusion of other objective causes of pain for at least 6 month of duration, and acceptance to complete the questionnaires at baseline and at 6 months of follow-up. Exclusion criteria included incomprehension of the contents of the questionnaires, history of fracture around the knee, tumour, infection, torn meniscus and anterior cruciate ligament injury. All patients underwent radiograph and MRI exams to rule out these conditions.

The following socio-demographic variables were recorded for all patients: sex, age, educational level and employment. After accepting to participate, the participants completed a booklet with the questionnaires at two moments: at baseline before treatment (physical therapy or surgery) and at 6 months after treatment completion. All the questionnaires were filled out by the patients themselves without assistance from any investigator. Selfreporting of clinical pain intensity was obtained by asking subjects to rate their pain during the past month on a Visual Analogue Scale (VAS) [1, 14]. The Lysholm Knee Scale was used to evaluate disability [34]. The frequency of patients' use of pain coping strategies was assessed with the Coping Strategies Questionnaire (CSQ) [28, 29]. Anxiety and depression were evaluated using the Hospital Anxiety and Depression Subscale (HAD) [13, 40]. Painrelated fear associated with avoidance behaviours and the avoidance of movement and physical activity was measured with the Tampa Scale for Kinesiophobia (TSK) [8, 17] and catastrophizing by means of the Pain Catastrophizing Scale (PCS) [11, 32].

The institutional review board (Hospital Arnau de Vilanova, ID number IC 2012/11) approved the protocol, and all patients gave their informed consent to participate in the study.

\section{Statistical analysis}

Descriptive statistics were calculated for the study sample, and scatter plots were used to detect outliers. Continuous variables were expressed with mean and standard deviation and categorical variables with raw number and percentage. Spearman correlation coefficients were used to explore the association between variables. For comparisons at each time point, pre- and post-treatment, repeated measures $t$ test were used. Finally, two multiple regression analyses were used to predict 6-month changes in the average pain intensity and disability after treatment. In each separate model, changes in pain and disability were the dependant variables, and age, sex, and changes in catastrophizing, kinesiophobia, anxiety and depression were the independent variables. Finally, the sensitivity of the changes in psychometric variables to detect changes was obtained by reporting the regression coefficients with $95 \%$ confidence intervals for those variables given by the model. The amount of change that predicts a change of $20 \mathrm{~mm}$ in pain and a change of 8.9 in disability were calculated, as these are the clinically relevant changes reported previously for VAS [37] and for Lysholm scale [2]. All statistical analyses were performed using SPSS software (SPSS Inc., Chicago, IL, USA), and statistical significance was determined using an $\alpha$ level of 0.05 .

\section{Results}

Of the 50 patients who began the study, 47 completed all the questionnaires at follow-up. Three patients had more 
Table 1 Demographic characteristics of the sample and variables before and after treatment

\begin{tabular}{|c|c|c|c|}
\hline Age & & & $2.1(10.9)$ \\
\hline Gender (no., $\%$ of female) & & & $42(89.4 \%)$ \\
\hline Studies & & & \\
\hline University & & & $17(36.1 \%)$ \\
\hline Secondary studies & & & $19(40.4 \%)$ \\
\hline Basic studies & & & $11(23.4 \%)$ \\
\hline & Initial & Follow-up & \\
\hline Examination characteristics & & & \\
\hline Pain (VAS) & $7.7(1.6)$ & $3.2(2.6)$ & $p<0.001$ \\
\hline Disability (Lysholm) & $43.9(20.9)$ & $73.5(20.6)$ & $p<0.001$ \\
\hline Pain coping strategies $(\mathrm{CS}$ & & & \\
\hline Diverting attention & $20.8(6.5)$ & $22.2(6.7)$ & n.s. \\
\hline Reinterpreting pain & $14.9(6.6)$ & $16.9(7.7)$ & n.s. \\
\hline Ignoring pain & $19.7(5.6)$ & $23.6(6.6)$ & $p<0.01$ \\
\hline Coping self-statements & $24.3(5.8)$ & $24.3(6.6)$ & n.s. \\
\hline Praying or hoping & $21.1(7.2)$ & $20.0(7.1)$ & n.s. \\
\hline Catastrophizing & $18.2(8.4)$ & $11.3(5.8)$ & $p<0.001$ \\
\hline Increasing activity level & $26.1(5.4)$ & $28.7(7.2)$ & n.s. \\
\hline Kinesiophobia (TSK) & $45.2(6.1)$ & $41.1(5.9)$ & $p<0.001$ \\
\hline Catastrophizing (PCS) & $20.7(13.1)$ & $7.5(10.2)$ & $p<0.001$ \\
\hline Anxiety (HAD) & $8.5(4.5)$ & $5.2(3.8)$ & $p<0.001$ \\
\hline Depression (HAD) & $5.7(4.3)$ & $2.8(3.1)$ & $p<0.001$ \\
\hline
\end{tabular}

than two unanswered items in one of the questionnaires and were excluded from the analysis. Five patients had only one item that went unanswered in one questionnaire, and they were not excluded because the unanswered item was in the middle value of the scale. Visual inspection of the scatter plot of each variable revealed no obvious outliers. Descriptive data for the sample are summarized in Table 1. After treatment there is a significant improvement in pain and disability levels. Among the pain coping strategies, as measured by the CSQ, only the subscale catastrophizing showed a significant reduction that was also shown with the specific questionnaire PCS. Similarly, anxiety, depression and kinesiophobia were significantly reduced after treatment.

Table 2 displays the Spearman rho correlations between both pain intensity and disability level with all the explored psychometric variables. After treatment, only anxiety, depression, catastrophizing and kinesiophobia correlated with residual pain and disability. The improvement changes in pain and disability after treatment significantly correlated with changes in anxiety, depression, kinesiophobia and catastrophizing, but not simultaneously with the other pain coping strategies. Change in catastrophizing turned out to be the strongest predictor of changes in both pain and disability after treatment.

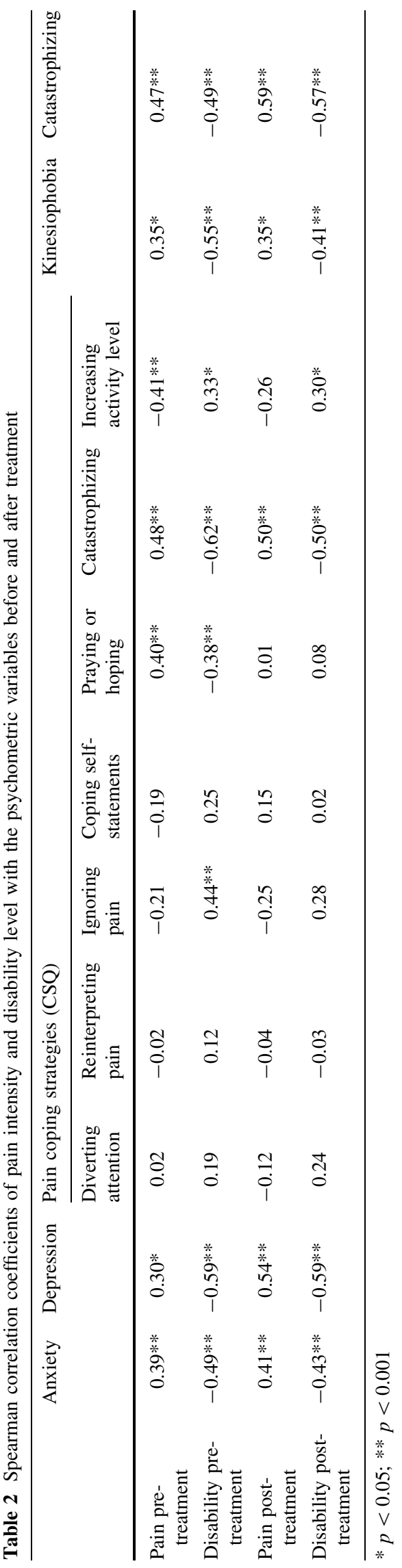


Table 3 Hierarchical regression explaining pain and disability

\begin{tabular}{lllll}
\hline Explanatory variables (change scores) & $R^{2}$ & Corrected $R^{2}$ & $B(95 \% \mathrm{CI})$ & $p$ value \\
\hline $\begin{array}{l}\text { Model predicting pain intensity } \\
\quad 0.49\end{array}$ & 0.48 & $0.13(0.09,0.17)$ & 0.001 \\
$\quad$ Catastrophizing (PCS) & 0.58 & 0.56 & & \\
$\begin{array}{l}\text { Model predicting disability } \\
\quad \text { Catastrophizing (PCS) }\end{array}$ & & & $-0.92(-1.42,-0.41)$ & 0.001 \\
Anxiety & & & $-2.26(-3.85,-0.67)$ & 0.006 \\
\hline
\end{tabular}

Two separate regression analyses were performed for pain and disability as dependant variables. Only changes in catastrophizing significantly predicted changes in pain level. Changes in catastrophizing accounted for $48 \%$ of the explained variance in changes in pain. Regarding disability, changes in catastrophizing and anxiety accounted for $56 \%$ of the variance. There were no colinearity problems in any of the coefficients obtained (Table 3).

Based on the non-standardized coefficients of the model, we calculated the clinically relevant changes in explanatory variables. A change of 15 points $(95 \%$ CI 12, 22) in catastrophizing measured with PCS predicts a clinically relevant change of two in pain intensity measured with VAS. Also, a change of 10 points $(95 \%$ CI 6, 22) in catastrophizing suggest a clinically meaningful change of nine in disability as measured by Lysholm scale.

\section{Discussion}

The most important finding of this study was that the changes in catastrophizing after treatment predict the changes in both pain and disability. As expected, on the basis of previous studies in chronic pain [7, 8, 16, 22, 23, 33 ], we found that catastrophizing was positively related to present pain intensity and disability among patients with anterior knee pain at the two time points of the study. After treatment, patients referred to a significant improvement in pain and disability, but most patients still had residual symptoms. This cross-sectional association between catastrophizing and pain is consistent with several prior investigations in other bone and joint conditions such as low back pain [22, 23], osteoarthritis of the knee [33], rheumatoid arthritis [16] and upper extremity conditions [7]. Thomeé et al. [36] observed in a sample of 50 patients with anterior knee pain that the catastrophizing subscale of the CSQ showed a very high score, more than double the score found in other series of rheumatoid arthritis patients.

In this study, the participation of changes in psychological variables on the changes in pain intensity and disability after treatment are also explored longitudinally. To our knowledge, this is the first study to address this issue in anterior knee pain patients. Changes in catastrophizing turned out to be the strongest predictor of change in referred pain intensity. After adjusting for sex, age, type of treatment, catastrophizing alone accounted for $48 \%$ of the explained pain variance. This finding is consistent with previous research that found an association between catastrophizing cognitions and the development of chronic pain in several musculoskeletal conditions and after an orthopaedic surgery [35].

Although the exact mechanisms by which catastrophizing affects the experience of pain and disability are not well known, it has been suggested that it influences pain perception and associated behaviour. People who catastrophize have difficulties in not focusing on the painful or threatening stimulus [6, 22]. This intensifies fear of pain, which increases attention paid to the stimulus. Also, an excessively emotional evaluation of pain is associated with catastrophizing, which causes a higher perception of the experience of pain [9]. In a study with functional MRI in patients with chronic pain, it was seen that ideas of catastrophizing were not only associated with a higher degree of activity in the brain's pain processing areas, but also in the cortical areas related to attention, the anticipation of pain, and emotional aspects of pain [12]. In a study performed in healthy subjects in whom pain was caused by heat, higher levels of pain catastrophization were related to a higher degree of pain as well as higher duration of the heat-related pain. This suggests that catastrophization plays a facilitator role in the pain perception process [9].

The observed reduction in catastrophizing levels after treatment is consistent with previous findings in patients having a total knee arthroplasty. Wade et al. [39] observed that as pain subsides after surgery for knee osteoarthritis, catastrophizing does as well. This observation challenges the notion of catastrophizing as a stable trait like a personality component. Pain is a multidimensional phenomenon composed of sensitive, cognitive-evaluative and affective-motivational domains. Catastrophizing modulates the perception of pain, and this relationship seems to be bidirectional in a dynamic manner. Our results suggest that anterior knee pain patients tend to catastrophize when pain is more intense. Conversely, some studies have shown in other chronic pain conditions that this relationship may occur in the opposite direction; as catastrophizing is primarily decreased, pain sensation and function improve $[4,31]$. 
In this study, the reduction in kinesiophobia showed a moderate correlation with improvement in disability and a low correlation with improvement in pain. These findings are consistent with a research by Piva et al. [24] who found that change in fear-avoidance beliefs about physical activity was the strongest predictor of function and pain outcome after rehabilitation in patients with anterior knee pain. In the study by Piva et al. [24] and also in ours, there was no specific treatment focused on modifying beliefs and attitudes, and the observed changes in fear beliefs were insignificant. It seems that the improvement in symptoms helped patients to overcome their fear of physical activity. Greater reduction in fear of movement beliefs have been reported in chronic low back pain using cognitive-behavioural treatments along with conventional biomedical treatment [19, 26].

This study has some limitations. An observational correlation design has been used, and therefore, causal inferences have to be made with caution. The sample was recruited from a specialized clinic in knee surgery which presumably treats the most severe cases. The average pain level of this sample was 7.7 in VAS from 0 to 10 , and the patient's symptoms persisted for more than 6 months. Maybe the associations found are lower in a sample with milder symptoms. Another weakness that may limit external validity of this study is that most of participants had high educational levels. Previous research has identified education and social function as potential moderators of catastrophizing's relationships with pain severity [10]. Additionally, we did not study the influence of structural abnormalities in the results after treatment. All patients were examined with MRI to rule out other causes of knee pain such as torn meniscus, ligamentous injury or osteoarthritis. However, the structural abnormalities that have been proposed to cause anterior knee pain such as spin, tilt, lateral translation and malalignment of the patella have been observed in many people with no knee pain or disease [15, 21]. Patients underwent either physiotherapy or surgical treatment by the same clinical team and with an homogeneous protocol. To prevent any potential interaction of the type of treatment received, this variable was entered in the regression model and failed to be predictive of the outcome. Further research is needed to specifically investigate the different impact of changes in beliefs and attitudes on the clinical outcome after physical therapy or surgery.

This study may have some clinical implications. As the clinical improvement in pain and disability has been shown to be associated with a reduction in catastrophizing and kinesiophobia, co-interventions to reduce catastrophizing thinking and kinesiophobia may improve the results of a purely biomedical treatment (physiotherapy or surgery). Studies performed in chronic low back pain have shown that interventions to decrease catastrophizing, fear of movement and anxiety help to improve functional status. Effective management of these maladaptative cognitions has been demonstrated with specific cognitive-behavioural strategies [3, 20, 27]. This study has provided preliminary evidence that reduction in catastrophizing may be an appropriate outcome measure, as it was sensitive to changes in pain intensity and disability. This study has also provided the amount of changes in catastrophizing necessary to observe a clinically meaningful change in pain intensity and disability that may help to calculate sample size in further interventional studies.

\section{Conclusion}

Clinical improvement in pain and disability has been shown to be associated with a reduction in catastrophizing and kinesiophobia. These findings suggest that co-interventions to reduce maladaptative beliefs and attitudes may improve the results.

\section{References}

1. Boeckstyns MEH, Backer M (1989) Reliability and validity of the evaluation of pain in patients with total knee replacement. Pain 38:29-33

2. Briggs KK, Lysholm J, Tegner Y, Rodkey WG, Kocher MS, Steadman JR (2009) The reliability, validity, and responsiveness of the Lysholm score and Tegner activity scale for anterior cruciate ligament injuries of the knee: 25 years later. Am J Sports Med 37:890-897

3. Brox JI, Sørensen R, Friis A, Nygaard Ø, Indahl A, Keller A, Ingebrigtsen T, Eriksen HR, Holm I, Koller AK, Riise R, Reikerås O (2003) Randomized clinical trial of lumbar instrumented fusion and cognitive intervention and exercises in patients with chronic low back pain and disc degeneration. Spine 28:1913-1921

4. Burns JW, Glenn B, Bruehl S, Harden RN, Lofland K (2003) Cognitive factors influence outcome following multidisciplinary chronic pain treatment: a replication and extension of a crosslagged panel analysis. Behav Res Ther 41:1163-1182

5. Chmielewski TL, Zeppieri G Jr, Lentz TA, Tillman SM, Moser MW, Indelicato PA, George SZ (2011) Longitudinal changes in psychosocial factors and their association with knee pain and function after anterior cruciate ligament reconstruction. Phys Ther 91(9):1355-1366

6. Crombez G, Eccleston C, Baeyens F (1998) When somatic information threatens, catastrophic thinking enhances attentional interference. Pain 75:187-198

7. De Das S, Vranceanu AM, Ring DC (2013) Contribution of kinesophobia and catastrophic thinking to upper-extremity-specific disability. J Bone Joint Surg Am 95:76-81

8. Domenech J, Sanchis-Alfonso V, Lopez L, Espejo B (2013) Influence of kinesiophobia and catastrophizing on pain and disability in anterior knee pain patients. Knee Surg Sports Traumatol Arthrosc 21:1562-1568

9. Edward RR, Smith MT, Stonerock G et al (2006) Pain-related catastrophizing in healthy women is associated with greater 
temporal summation of and reduced habituation to thermal pain. Clin J Pain 22:730-737

10. Edwards RR, Giles J, Bingham CO III, Campbell C, Haythornthwaite JA, Bathon J (2010) Moderators of the negative effects of catastrophizing in arthritis. Pain Med 11:591-599

11. García Campayo J, Rodero B, Alda M, Sobradiel N, Montero J, Moreno S (2008) Validación de la versión española de la Pain Catastrophizing Scale en pacientes con fibromialgia. Med Clin 131:487-492

12. Gracely RH, Geisser ME, Giesecke T (2004) Pain catastrophizing and neural responses to pain among persons with fibromyalgia. Brain 127:835-843

13. Herrero MJ, Blanch J, Peri JM et al (2003) A validation study of the hospital anxiety and depression scale (HADS) in a Spanish population. Gen Hosp Psychiatry 25:277-283

14. Jensen MP, Karoly P, O'Riordan EF, Bland F Jr, Burns RS (1989) The subjective experience of acute pain: an assessment of the utility of 10 indices. Clin J Pain 5:153-159

15. Johnson LL, van Dyk GE, Green JR (1998) Clinical assessment of asymptomatic knees: comparison of men and women. Arthroscopy 14:347-359

16. Keefe FJ, Affleck G, Lefebvre JC (1997) Pain coping strategies and coping efficacy in rheumatoid arthritis: a daily process analysis. Pain 69:35-42

17. Kori KS, Miller RP, Todd DD (1990) Kinesiophobia: a new view of chronic pain behaviour. Pain Manag 3:35-43

18. Leeuw M, Goossens ME, Linton SJ, Crombez G, Boersma K, Vlaeyen JW (2007) The fear-avoidance model of musculoskeletal pain: current state of scientific evidence. J Behav Med 30:77-94

19. Leeuw M, Goossens ME, van Breukelen GJ, de Jong JR, Heuts PH, Smeets RJ, Köke AJ, Vlaeyen JW (2008) Exposure in vivo versus operant graded activity in chronic low back pain patients: results of a randomized controlled trial. Pain 138:192-207

20. Linton SJ, Nordin E (2006) A 5-year follow-up evaluation of the health and economic consequences of an early cognitive behavioral intervention for back pain: a randomized, controlled trial. Spine 15:853-858

21. Macintyre NJ, Hill NA, Fellows RA (2006) Patellofemoral joint kinematics in individuals with and without patellofemoral pain syndrome. J Bone Joint Surg 88A:2596-2605

22. Peters ML, Vlaeyen JWS, Weber WEJ (2005) The joint contribution of physical pathology, pain-related fear and catastrophizing to chronic back pain disability. Pain 113:45-50

23. Picavet HSJ, Vlaeyen JWS, Schouten SAG (2002) Pain catastrophizing and kinesiophobia: predictors of chronic low back pain. Am J Epidemiol 156:1028-1034

24. Piva SR, Fitzgerald GK, Wisniewski S, Delitto A (2009) Predictors of pain and function outcome after rehabilitation in patients with patellofemoral pain syndrome. J Rehabil Med 41:604-612

25. Powers CM, Bolgla LA, Callaghan MJ, Collins N, Sheehan FT (2012) Patellofemoral pain: proximal, distal, and local factors, 2nd international research retreat. J Orthop Sports Phys Ther 42:A1-A54

26. Rainville J, Smeets RJ, Bendix T, Tveito TH, Poiraudeau S, Indahl AJ (2011) Fear-avoidance beliefs and pain avoidance in low back pain-translating research into clinical practice. Spine J 11:895-903

27. Riddle DL, Wade JB, Jiranek WA, Kong X (2010) Preoperative pain catastrophizing predicts pain outcome after knee arthroplasty. Clin Orthop Relat Res 468(3):798-806

28. Rodríguez Franco L, Cano García FJ, Blanco Picabia A (2004) Evaluación de las estrategias de afrontamiento del dolor crónico. Actas Esp Psiq 32:82-91

29. Rosenstiel AK, Keefe FJ (1983) The use of coping strategies in chronic low back pain patients: relationship to patient characteristics and current adjustment. Pain 17:33-44

30. Sanchis-Alfonso V (2014) Holistic approach to understanding the anterior knee pain. Clinical implications. Knee Surg Sports Traumatol Arthrosc (in press)

31. Smeets RJ, Vlaeyen JW, Kester AD, Knottnerus JA (2006) Reduction of pain catastrophizing mediates the outcome of both physical and cognitive-behavioral treatment in chronic low back pain. J Pain 7:261-271

32. Sullivan HJL, Bishop SR, Pivik J (1995) The Pain Catastrophizing Scale: development and validation. Psychol Assess 7:524-532

33. Sullivan M, Tanzer M, Stanish W, Fallaha M, Keefe FJ, Simmonds M, Dunbar M (2009) Psychological determinants of problematic outcomes following total knee arthroplasty. Pain 143:123-129

34. Tegner Y, Lysholm J (1985) Rating systems in the evaluation of knee ligament injuries. Clin Orthop Relat Res 198:43-49

35. Theunissen M, Peters ML, Bruce J, Gramke HF, Marcus MA (2012) Preoperative anxiety and catastrophizing: a systematic review and meta-analysis of the association with chronic postsurgical pain. Clin J Pain 28:819-841

36. Thomeé P, Thomeé R, Karlsson J (2002) Patellofemoral pain syndrome: pain, coping strategies and degree of well-being. Scand J Med Sci Sports 12:276-281

37. Tubach F, Ravaud P, Baron G, Falissard B, Logeart I, Bellamy N, Bombardier C, Felson D, Hochberg M, van der Heijde D, Dougados M (2005) Evaluation of clinically relevant states in patient reported outcomes in knee and hip osteoarthritis: the patient acceptable symptom state. Ann Rheum Dis 64:34-37

38. Vlaeyen JW, Linton SJ (2000) Fear-avoidance and its consequences in chronic musculoskeletal pain: a state of the art. Pain $85: 317-332$

39. Wade JB, Riddle DL, Thacker LR (2012) Is pain catastrophizing a stable trait or dynamic state in patients scheduled for knee arthroplasty? Clin J Pain 28:122-128

40. Zigmond AS, Snaith RP (1983) The hospital anxiety and depression scale. Acta Psychiatr Scand 67:361-370 